\title{
Reflexiones sobre el
}

\section{movimiento estudiantil}

\section{parlamentarista del Colegio Humanístico Costarricense}

\section{Reflections on Student Parliamentary Movement at the Costa Rican Humanistic Secondary School}

\author{
Andrés Villafuerte Vega \\ Exalumno del Colegio Humanístico Costarricense \\ Universidad Nacional, Campus Omar Dengo \\ andres.villafuerte@ucr.ac.cr
}

\section{Resumen}

El presente artículo tiene como objetivo explicar los motivos, repercusiones, esperanzas y críticas del movimiento estudiantil parlamentarista, surgido en el Colegio Humanístico Costarricense (campus Omar Dengo) a partir del año 2012. Este movimiento nació con el propósito de criticar las desavenencias ocurridas alrededor de la administración pública, a raíz de una problemática en el propio sistema político costarricense. Sin embargo, también se ofrecieron algunas de las posibles medidas para dar solución a dichos problemas, de las cuales destaca el cambio en la forma de gobierno. Cabe resaltar que este movimiento fue y continúa siendo exclusivo del estudiantado, con la debida asesoría del cuerpo docente y administrativo de la institución. Asimismo, se pretende describir cuál es el aporte del Humanismo en la política estudiantil.

Palabras clave: Movimiento estudiantil, democracia, sistemas políticos, humanismo, participación ciudadana 


\begin{abstract}
This article aims to explain the reasons, consequences, hopes, and critics of the student parliamentary movement that came up at the Costa Rican Humanistic Secondary School (Omar Dengo Campus) as of 2012. This movement arose with the purpose of criticizing the disagreements at the public administration level due to problems within the Costa Rican political system. Possible measures are proposed to solve these problems. One proposal that stands out is a change in the form of government. This movement was, and still is, exclusive to the students, with the advice of teaching and administrative staff of the institution. Likewise, the article aims to describe the contribution of Humanism to student politics.
\end{abstract}

Keywords: Student movement, democracy, political system, humanism, citizen participation.

\title{
Introducción
}

El gobierno estudiantil del Colegio Humanístico Costarricense del Campus Omar Dengo, que a diferencia de otras instituciones de educación secundaria en el país, tiene como base un sistema político parlamentarista.

Permítanme rememorar un poco la historia y motivos de tal decisión, para luego describir el significado, las críticas y las repercusiones de dicho movimiento.

El Colegio Humanístico Costarricense, desde su fundación en 1998, nunca contó con un organismo de representación estudiantil. En aquel entonces no se hizo necesario, debido, entre otras razones, al pequeño grupo de alumnos y a la rudimentaria comunicación entre estos y las autoridades colegiales.

No obstante, con el paso del tiempo y el aumento en el número de estudiantes, el diálogo fue más complejo, hasta hacerse cada vez más clara la necesidad de instaurar un gobierno estudiantil, con el propósito de ser una vía de comunicación directa, además de incidir en las decisiones que competían, también, al estudiantado.

Cuando el estudiantado expuso tal necesidad, la administración del Colegio pidió la asesoría correspondiente para instaurar un organismo de representación estudiantil. Por ende, como es costumbre, el Ministerio de Educación Pública invitó a ciertos estudiantes del colegio, acompañados del profesor Roberto Rojas Benavidez, a ser parte de una serie de capacitaciones impartidas por sus propios funcionarios. 
Estas reuniones tenían el propósito de explicar el entramado y funcionamiento de los gobiernos estudiantiles, con base en el Reglamento para la Organización y Funcionamiento del Gobierno Estudiantil (Decreto Ejecutivo n. ${ }^{\circ}$ 35333-MEP) y en el Código Electoral Estudiantil (Decreto Ejecutivo n. ${ }^{\circ}$ 35337-MEP).

Es importante aclarar que los organismos de representación estudiantil debían basarse en sistemas políticos presidencialistas. Así que las capacitaciones que recibíamos desilusionaron mucho al grupo de alumnos. Se denotó una clara crisis en los gobiernos estudiantiles colegiales, reflejo del propio sistema político del gobierno nacional. La falta de seriedad en las elecciones institucionales, el poco compromiso asumido al obtener el poder, el despilfarro de dinero en propagandas basadas en imágenes y no en ideas, la mínima incidencia ciudadana y estudiantil a los procesos que les competen, la abstinencia electoral, la ausencia de control político, entre otras muchísimas situaciones: ejemplo claro del estado en el que se encuentran los sistemas representación política estudiantil.

Esta desilusión, consecuencia de una vasta actividad reflexiva, se debió a dos motivos, principalmente. El primero es la propia experiencia del estudiantado en sus antiguos colegios, donde se vivían, una y otra vez, las situaciones antes mencionadas (en el caso de que hubiera elecciones estudiantiles, pues recuerdo a varios compañeros que comentaban que en su colegio ni siquiera existía gobierno estudiantil, por la poca incidencia y apatía del estudiantado).

El segundo motivo, se debe a una conciencia adquirida en torno a la política nacional y a necesidad en una participación ciudadana concisa y efectiva, producto del Taller de Formación Política y Participación Ciudadana, curso extracurricular impartido por los profesores Roberto Rojas (ex profesor de Pensamiento Contemporáneo y actual Decano del Centro de Estudios Generales) y Manuel Rojas (profesor de Historia y Sociedad), junto a otros invitados especiales.

Tras una extensa discusión entre el estudiantado, se llegó a la conclusión de que instaurar una sistema presidencialista como forma de gobierno sería condenar al naciente movimiento estudiantil para que, en el futuro, fuera víctima de las artimañas de la desidia, la apatía, la negligencia y la banalidad. Empero, se mantenía la necesidad de contar con un organismo de representación estudiantil, por lo que surgió la duda sobre cuál sería el mecanismo idóneo para fortalecer la política estudiantil institucional. 
Los estudiantes nos dimos a la tarea de analizar las distintas formas de gobierno en el mundo contemporáneo. Al final de cuentas, después de un cuantioso descarte, quien salió victorioso fue el parlamentarismo. Más adelante expondré los motivos.

$\mathrm{Al}$ analizar esta particular forma de gobierno, invitamos a varios expertos sobre el tema, de los cuales se mencionan Carlos Humberto Cascante (director de la Escuela de Relaciones Internacionales de la Universidad Nacional), Boris Ramírez (periodista y actual Jefe de Prensa de Casa Presidencial) y Juan Diego Gómez (ex presidente de la FEUNA y actual profesor de Pensamiento Contemporáneo en el Colegio Humanístico Costarricense).

Después de este arduo proceso, el estudiantado del Colegio Humanístico Costarricense, en el año 2012, se sienta en la mesa de negociación junto a las autoridades académicas y administrativas del mismo colegio y de la Universidad Nacional. "Tras un consistente diálogo, la administración, la docencia y el estudiantado se ponen de acuerdo, y por primera vez (después de catorce años de fundación) se tienen las primeras elecciones estudiantiles”, tal y como fue mencionado en un discurso ofrecido para el Traspaso de Poderes 2014-2015 (viernes 9 de mayo del 2014, Auditorio Clodomiro Picado).

Se nos dio la victoria e instauramos un gobierno estudiantil parlamentarista, aprovechando la libertad que le fue conferida al Colegio, mediante el art. 2 del Decreto Ejecutivo $\mathrm{N}^{\circ}$ 26436-MEP (norma en la cual se fundan las bases de la institución); cuyo contenido dicta:

Los Colegios Humanísticos Costarricenses tendrán un régimen diferente al de todos los colegios oficiales, en razón de sus fines y propósitos; su plan de estudios, contenidos programáticos; nivel de exigencia; reglamentos; currículo; organización propia; normas particulares de admisión y promoción; criterios de contratación de personal docente y administrativo; calendario escolar propio y otros aspectos.

De esa forma, el Colegio Humanístico Costarricense forjó las bases del primer sistema de gobierno estudiantil parlamentarista, en toda la historia nacional. 


\section{El pregonar del movimiento}

Un sistema político es la base jurídica institucional que interviene en la dinámica política de la comunidad en cuestión. Tales bases deben ser sólidas, sino "el edificio” se desmorona. Un pequeño error en una de las raíces, repercute en todo el resto (Zúñiga y Jiménez, 2013, pp.4-6).

Es evidente que, en nuestro país, es cada vez mayor el número de problemáticas que debemos enfrentar. Por ejemplo, en cada Informe del Estado de la Nación se denota el aumento en la cifra de malas noticias, en comparación a unas pocas buenas.

Algo está debilitando y carcomiendo la política nacional y, por ende, toda la forma de manejar este país tiene severos problemas. Es como el efecto dominó. Para colmo, en vez de encontrar soluciones, los problemas aumentan, se salen de las manos de los gobernantes y también de los gobernados.

Con el transcurrir de los años, ciertas ramas del gran árbol político del país se han debilitado mucho, mientras otras aún gozan de estabilidad. Nosotros, en el Colegio Humanístico Costarricense, identificamos, con base en lo anterior, que la debilidad provenía desde una raíz, que tiene por nombre "sistema presidencialista". Es nuestra mira para criticar y para proponer soluciones, pues para los estudiantes de la mencionada institucional, criticar sin ser propositivo es destruir, nada más. La crítica propositiva es la única que puede construir y edificar.

No se descarta el yerro en dicho análisis. Quizá el problema sea más grande o más pequeño, pero mantenemos la seguridad, aún pasado el tiempo, de que el sistema presidencialista tiene carencias para las necesidades del pueblo costarricense.

Asimismo, desde una visión simplista, para que un grupo de estudiantes anticipara que con un sistema presidencialista su representatividad podría verse afectaba por ciertos antivalores políticos y ante la clara percepción de los errores cometidos dentro del propio sistema político costarricense, algo malo estaba sucediendo.

Tales razones y motivos fueron suficientes para adoptar una distinta forma de gobierno, con el compromiso perpetuo de mantener un trabajo incansable y un esfuerzo conjunto de toda la comunidad orgánica de la institución, en miras de dar a conocer nuestro punto de vista con respeto a esta problemática y ofrecer nuestras soluciones. 
Por esto mismo, el movimiento estudiantil parlamentarista del Colegio Humanístico Costarricense, no nació para alardear, como otros. Este inició para mantener viva una crítica contra lo que destruye nuestro sistema de gobierno costarricense y buscar los remedios adecuados para fortalecer (y casi resucitar) la debilitada política costarricense.

Por lo antes mencionado, se defiende que la problemática de nuestro país se encuentra en su sistema político y no en otra área. Si se soluciona la raíz, el árbol tiene mayores posibilidades de sanar. De nada sirve podar ramas enfermas que pueden resurgir (cito el caso de la corrupción). Además, no todas las ramas están enfermas. Por ejemplo, Costa Rica, a lo largo del tiempo, ha demostrado estar a la vanguardia con respecto a ciertos valores políticos y civiles, en comparación con otros países en la región, de las cuales podemos mencionar, de entre muchos casos, los siguientes, según Sáenz (2012, pp.451, 467, 472,493):

- Esta nación es la democracia más antigua de América Latina.

- Ha luchado por la paz entre los pueblos, con acciones como la abolición de la pena de muerte y la del ejército como institución permanente o la labor por alcanzar la paz en América Central entre las décadas de 1980 y 1990, por mencionar algunos.

- Es uno de los primeros países del mundo en legitimar los Derechos Humanos, sin contar que en esta nación se instauró el primer tribunal de Derechos Humanos en toda la historia mundial, en la ciudad de Cartago en 1908, con el nombre de Corte de Justicia Centroamericana.

- La constante necesidad de salvaguardar la biodiversidad, a través de la instauración de miles de kilómetros cuadrados como áreas protegidas.

- El poder y la intervención ciudadana, aunque con ciertos rezagos, ha estado siempre presente. Cito las manifestaciones de ALCOA, el Combo ICE, el referéndum por el TLC con Estados Unidos, el movimiento sindicalista o la utilización de las garantías ofrecidas por la Sala Constitucional para hacer contrapeso a los políticos. Resalto, además, las últimas elecciones nacionales y municipales, donde la ciudadanía ha ido quebrantando, sin cabida a la duda, el bipartidismo imperante desde hace décadas.

Como se puede observar, esos valores y virtudes propias del país no son las debilidades de la política nacional. Sin embargo, estos recién mencionados, 
pueden verse afectados si la problemática del sistema político se hace cada vez más creciente. Es contundente, por ende, decir "manos a la obra” y, de una vez por todas, dar solución a las contrariedades de nuestro país. Para ello, Albert Einstein insta, diciendo lo siguiente: "Si quieres resultados distintos, no hagas siempre lo mismo".

Algunas de las problemáticas presentes en el sistema presidencialista costarricense, a continuación, serán mencionadas. Asimismo, se relata cuál fue la medida curativa propuesta para combatir dicho problema, a partir de la experiencia recibida en nuestro sistema parlamentarista colegial. (Aclaración: si usted está muy relacionado con las actividades de la Universidad Nacional, es posible que haya escuchado estas mismas palabras, más aún si asistió al IV Encuentro de Humanistas, al VII Foro de Debates de Pueblos y Culturas de las Américas o a las Jornadas del Centro de Estudios Generales en el año 2013).

La principal y más fuerte crítica fue contra el centralismo imperante en esta forma de gobierno. El presidencialismo (tal y como lo indica su nombre) coloca a una sola persona (el presidente) en el centro del régimen. Por ende, los demás funcionarios públicos quedan subordinados ante su autoridad casi omnipotente; el cual, si no fuera por el principio de legalidad, a través de la Constitución Política y el sistema de pesos y contrapesos, no tendría límites.

Lo anterior pone en peligro los intereses esenciales de la comunidad, pues es permisiva en cuanto esa única persona al mando ponga sus intereses antes de los de su pueblo. Asimismo, las personas trabajadoras alrededor del gobernante (en nuestro país, los ministros) son invisibilizados ante la presencia de su jefe. Esto es un arma de doble filo, pues si uno de ellos comete un grave error, quien recibe la mayor cantidad de achaque popular, es el presidente y no el culpable. Además, ante este anonimato, ¿cómo hace el pueblo para exigirle cuentas a un desconocido? Es necesario que todos los funcionarios estén "en el podio", para poder señalar sus errores, como también sus virtudes. Sobra resaltar que este fenómeno es consecuencia de los anticuados vestigios heredados del absolutismo monárquico de la Colonia y del caudillismo en América Latina (Cervantes, 1987, pp.46-47).

La solución que se le dio a este fenómeno en el Colegio Humanístico Costarricense fue instaurar un gobierno "sobre varios hombros”. No existe presidente, ni ningún tipo de junta directiva. El sistema parlamentario colegial se instauró en cuatro entes gubernamentales: el Parlamento Estudiantil, el Órgano Ejecutivo, la Contraloría 
Estudiantil y el Tribunal Electoral Estudiantil. En cada uno de ellos existía un jerarca inmediato, quien era supervisado por los mismos miembros del ente y controlado (como en un sistema de pesos y contrapesos) por los demás jerarcas.

Estos eran la Jefatura del Parlamento, el Primer Ministerio, la Contraloría y la Presidencia del Tribunal Electoral Estudiantil. De esa forma, ningún funcionario del gobierno estudiantil podía ser invisibilizado.

El centralismo, además de las nefastas consecuencias antes mencionadas, produce un peor fenómeno. Este es la estructuración de campañas políticas basadas en imágenes y no en ideas. Es decir, el proselitismo en tiempo electoral es mirar los "rostros lindos" de los candidatos junto a situaciones conmovedoras (por ejemplo: el típico abrazo al anciano, al pobre y al bebé). Para ellos, es necesario crear una imagen humana y cálida del candidato y así obtener la aprobación del pueblo, mejor aún si utilizan el ideario del ser costarricense (con chonete y pañuelo en mano, ojalá en alguna monta de toros o un tope). Por tanto, el pueblo elector llega conocer hasta la vida íntima del aspirante (por ejemplo, cuántos trajes y relojes tiene), pero tiene poco acceso a su plan de gobierno, sus propuestas y métodos de acción, su ideología, su visión futuro y, mucho menos, su equipo de trabajo. Este tipo de campaña política no trata de convencer, sino de manipular. Cada 8 de mayo, asume la presidencia quien mejor supo sonreír (Muñoz y otros, 2009, pp.17).

La reacción del estudiantado del Colegio, contra este tipo de campañas fue radical. Se prohibieron del todo. El Humanístico no iba a caer en las trampas de hacer campañas políticas colegiales con pasarela de modelos, conciertos o con la contratación de personajes públicos para obtener el voto fácil, como si fuera "la moda". Estábamos decididos a no caer en dicha ridiculez, la cual tanto nos desilusionó en nuestros antiguos colegios y deslegitima el accionar de los gobiernos estudiantiles.

En nuestras campañas políticas están prohibidas el uso de fotografías, impresiones y cualquier aparato tecnológico. Además, las pancartas, rótulos u hojas utilizadas como proselitismo debían provenir de materiales reutilizados. En el 2012, la semana electoral tuvo un costo total de $\$ 20000$, pero con el pasar de los años el monto ha venido disminuyendo. Asimismo, solo para inscribir el partido político, es necesario presentar un plan de gobierno muy detallado, divido por enfoques de acción, el cual es seriamente criticado o aplaudido durante los dos debates realizados por el Tribunal Electoral Estudiantil. 
De hecho, en uno de los discursos de la toma de posesión, se denunció este fenómeno, cuando se dijo: "Esta es la causa de que se den campañas de imagen y no de propuestas ideológicas, porque parece ser más fácil sonreír frente a una cámara que sudarse la camisa con el pueblo” (Vargas, 2013, p.47).

Otro fenómeno relacionado con el centralismo es la poca importancia dada, por la ciudadanía en general, a los procesos de la Asamblea Legislativa. A esto se le une la poca madurez política en los gobernantes, que obtienen como resultado el constante deterioro del comportamiento legislativo. Es preciso hacerle recordar a todos los costarricenses que parte fundamental del progreso de nuestra nación está en el trabajo de los diputados, quienes, al fin de cuentas, deben ser el micrófono para amplificar nuestras opiniones. Sin embargo, claro está, la realidad no es así. Da risa ver la transmisión en vivo del plenario. El zafarrancho y la pérdida de seriedad, son miembros recurrentes a las sesiones (a veces también se hacen presentes el sueño en plena sesión o el receso prolongado, para deleitarse con los lujosos refrigerios). Todo esto se resume en retraso en la aprobación de leyes, incapacidad en la toma de decisiones, acumulación de proyectos de ley, debilitamiento de la consulta popular, aprobación de leyes innecesarias o ineficaces y la tendencia a heredar proyectos a los gobiernos postreros (Programa Estado de la Nación, 2014, pp.254-256).

Por ende, es necesaria una transformación del comportamiento legislativo y (¿por qué no?) ejecutivo del país. Por eso, Álvaro Mora nos apoya, cuando escribe:

Sí planteásemos un cambio en la relaciones Poder Ejecutivo-Poder Legislativo necesariamente tendríamos que remitirnos al análisis de pasar de un sistema presidencialista puro y clásico a un sistema semipresidencialista o semiparlamentario como un forma de solventar la crisis que se pudiese estar configurando a causa de un agotamiento del sistema imperante. (Hines, 2011, p.221).

En este mismo sentido, es imposible no tocar el tema del número de partidos políticos representados en la Asamblea Legislativa. En las últimas elecciones nacionales, fue claro el clamor del pueblo costarricense por abolir el bipartidismo imperante en el país desde mediados del siglo XX. Su soberanía instauró en el poder a un partido político que nunca antes había alcanzado tal posición. Ni qué decir del órgano legislativo, el cual quedó dividido en nueve fracciones diferentes, ninguna con mayoría parlamentaria. En pocas palabras: "el bipartidismo ha 
muerto, lo han matado los hombres”. Sin embargo, en ciertas personas aún trata de revivir ese pasado y no confrontar la realidad. El mismo Reglamento de la Asamblea Legislativa es una prueba de ello, donde aún sobreviven los rastros del bipartidismo, que afectan, pues, el diálogo, la discusión y la negociación entre los diputados. Si en sus mentes, no logran entender la muerte de la época de enemistad perpetua y competencia, no lograrán hacer grandes aportes a la sociedad, pues, en estos momentos, es necesario forjar alianzas partidarias para alcanzar sus objetivos. Si no hay comunicación, no hay alianzas. (Programa Estado de la Nación, 2014, pp.245-247).

En el Colegio Humanístico, con un claro panorama de todo lo anterior, le brindó especial atención al origen de la palabra parlamento, la cual desciende del verbo francés parler, que traducido al español corresponde a hablar. Dentro de nuestro sistema parlamentarista, se ha cuidado siempre que la comunicación, el diálogo, la negociación y la sana discusión estén presentes en todo proceso. No solo con la comunidad de electores, sino también entre las mismas fuerzas políticas y los entes gubernamentales, sin dejar de lado el intercambio con las autoridades docentes y administrativas de la institución.

Es necesario recalcar que dentro del sistema parlamentarista, el Órgano Ejecutivo (el primer ministro y las demás secretarías) es designado por el Parlamento Estudiantil. Es decir, no son puestos de elección popular, como suele pasar en el sistema presidencialista. Por ende, los parlamentarios deben sentarse, por un buen rato, en la mesa de negociación, para deliberar quien es la persona más idónea para tomar el cargo correspondiente. Esta actividad se conoce como la sesión solemne. Desde la instauración del gobierno estudiantil, el Órgano Ejecutivo siempre habría estado conformado por miembros de distintos partidos, lo cual incrementa el diálogo interpartidario.

Humberto Maturana (1995), explica lo siguiente sobre la democracia:

La democracia surgió en el Ágora, en el mercado, que era el sitio donde se sentaban los ciudadanos a conversar de todo. Por supuesto que los ciudadanos eran los terratenientes, artesanos, comerciantes, etc. Pero en el Ágora se juntan todos y conversan. Y ¿De qué conversan? De los temas de la comunidad. Conversan como iguales porque son todos de una misma clase y los temas de la comunidad les interesan y en estas conversaciones 
surge la cosa pública. Cuando se reúnen a hablar de los asuntos que a todos interesan los temas de la comunidad se hacen públicos. (p.24)

En Costa Rica hay una peligrosa contradicción, pues los temas de la comunidad no son de manejo público, debido al notable desinterés. Muchos ciudadanos, al ver la persistencia de los errores del gobierno, se desilusionaron y adoptaron apatía en torno a todo el engranaje político del país. Por ello, la abstinencia electoral y la pérdida de confianza es cada vez más creciente. Parece existir un imponente olvido sobre el significado e importancia de una democracia real y efectiva, pues acá no es la comunidad, en su conjunto, quienes deciden el futuro de la nación. Asimismo, aunque el presidencialismo y el parlamentarismo son sistemas representativos, se debe buscar la manera de transformarlos en participativos. La intervención ciudadana es imprescindible en los procesos políticos, porque es la única garantía de construir, de verdad, un país para y por la ciudadanía (Delgado, 2012, pp.455-456).

Los mecanismos de control político son excelentes herramientas para aumentar la participación ciudadana y la confianza política. Véase, por ejemplo, cómo el pueblo costarricense utiliza las garantías de la Sala Constitucional para poner freno a los proyectos que no reflejan los intereses de la ciudadanía. Sin embargo, se necesita de algo más.

En el Colegio Humanístico le dimos seriedad al voto de censura, la cual es una solicitud ciudadana para destituir a un funcionario público (pérdida de las credenciales), en caso de incumplir sus obligaciones o por no trabajar en beneficio del pueblo. Esto, de forma inconsciente, fomenta un trabajo serio por parte de los políticos, con cautela, transparencia y rendición de cuentas, pues conocen que la opinión pública los puede quitar de su preciado cargo. Desde la instauración del gobierno estudiantil hasta la actualidad, se han aplicado alrededor de siete votos de censura.

El abstencionismo y la falta de confianza en los procesos políticos y los gobernantes han conducido a una problemática peor. La juventud siempre ha buscado la manera de ofrecer soluciones y externar sus opiniones. Sin embargo, por el adultocentrismo reinante en nuestro país (y en América Latina), no existen los mecanismos para que las poblaciones juveniles logren hacer escuchar su voz. Por ende, es común la realización actos de violencia, vandalismo y anarquía para llamar la atención (Romero, 2000, p.45). 
La manifestación pública es un acto de libre expresión, pero debe limitarse cuando pretenda dañar la integridad física o emocional de terceras personas. Asimismo, cuando los partidos políticos intentan dar representatividad a la juventud, lo hacen con una participación mínima (por ejemplo, solo una persona joven en toda la nómina de diputados). Para colmo, en los últimos treinta años de historia en Costa Rica, los políticos más jóvenes han desilusionado al pueblo costarricense por casos de corrupción, escándalos sexuales o por padecer ignorancia (Villasuso, 2003, p.218).

No obstante, desde hace unos años, los partidos políticos han fortalecido los medios para que dichas personas accedan a puestos de elección popular. Así, por ejemplo, en las últimas elecciones municipales, algunos jóvenes obtuvieron sillas en los Consejos Municipales, mientras otros alcanzaron ciertas Vicealcaldías. Asimismo, el actual Gobierno de la República, también tiene en su haber personas jóvenes en viceministerios.

El Humanístico se ha destacado con cada proceso electoral estudiantil. Con ello se le dice al pueblo costarricense que aún persiste un grupo de jóvenes interesados en hacer las cosas de la manera correcta. Solo solicitamos el espacio y las oportunidades para externar estas opiniones y demostrar muchas capacidades. Ejemplo de esto, entre otros, son los logros de los siguientes proyectos:

- Consolidación de la Constitución Política del Colegio Humanístico Costarricense, donde se estructura toda la base jurídica de los futuros procesos políticos colegiales.

- Configuración del Sistema Tributario, donde se fundaron las bases de la recaudación de impuestos estudiantiles, para garantizar la independencia económica de las autoridades administrativas de la institución y así salvaguardar los intereses del estudiantado.

- Reapertura de la biblioteca institucional, a través de su nombramiento, el cual hace honor a la escritora costarricense Carmen Lyra.

- Creación de la Secretaría de Ambiente, cuyo principal objetivo es fomentar el cuido y constante restauración del entorno.

- Instauración del Sistema Estudiantil de Fraternidades, donde los estudiantes comparten sus gustos y expectativas relacionadas con diversas áreas del saber. 
- Manteamiento de diversos proyectos relacionados con la vida de la población estudiantil, conforme a las necesidades e intereses de sus integrantes.

- Búsqueda por consolidar el mismo proyecto en las demás instituciones del Sistema de Colegios Humanísticos Costarricenses.

\section{Consecuencias internas y externas del movimiento}

Cuando el Colegio Humanístico publicó la noticia sobre la instauración estudiantil de un gobierno parlamentarista, las reacciones no se hicieron esperar. La prensa fue la primera en acudir, para correr la voz de lo que estaba pasando. Estas fueron las publicaciones de los medios de comunicación, durante el año 2012 (en años posteriores, algunos medios de comunicación continuaron brindando seguimiento al proceso estudiantil):

- Viernes 8 de junio: Telenoticias, programación de Teletica, expone una nota periodística en la edición meridiana.

- Sábado 16 de junio: Visión Crítica, programación de Radio Nacional, dedica una edición para exponer el sistema parlamentario del Colegio Humanístico Costarricense.

- Domingo 17 de junio: Revista Dominical del Periódico La Nación publica un artículo titulado "Un 'cole' con diputados".

- Lunes 23 del julio: UNA Mirada, programación de SINART S.A., dedica una edición para hablar de "Juventud y Participación Ciudadana”, con miembros del Colegio Humanístico Costarricense y del Centro de Estudios Generales de la UNA.

- Mes de Julio: El boletín informativo CAMPUS de la UNA publica un artículo titulado "Colegio Humanístico elige Primera Ministra”.

- Mes de agosto: El boletín informativo CAMPUS de la UNA publica un artículo titulado "Mónica, parte del cambio".

De esta forma, muchísimas personas se enteraron de nuestras propuestas. Algunos las apoyaron, otros las rechazaron del todo. Así, por ejemplo una profesora de la Universidad de Costa Rica se refirió con términos elogiosos a lo que "un grupo de muchachos hacían con su gobierno estudiantil en el Humanístico”. La mayoría de egresados de la institución dieron todo su apoyo a la iniciativa de sus compañeros menores. 
De las instituciones públicas, la Universidad Nacional siempre mostró un gran apoyo y aprobación, en especial el Centro de Estudios Generales, con los cuales compartimos, más de una vez, algún debate, conversación o intercambio de ideas. Igual situación ocurrió con la Municipalidad de Heredia.

El Ministerio de Educación Pública también mostró su apoyo, al menos los jerarcas de la Supervisión Circuital y la Dirección Regional de Heredia. Sin embargo, al tiempo nos enteramos de que ciertos funcionarios (no los antes mencionados) repudiaron la idea y criticaron fuertemente el "acto de rebeldía" de esos estudiantes hacia la democracia costarricense.

Al tiempo de realizar la Toma de Posición, recibimos una visita muy amena por parte de algunos funcionarios del Instituto de Formación y Estudios en Democracia, del Tribunal Supremo de Elecciones. Con ellos nos reunimos todos los funcionarios colegiales de los cuatro entes del gobierno estudiantil y les explicamos lo mismo que he relatado en el presente artículo. Se llevaron una impresión muy grande de nosotros, pues al poco tiempo solicitaron nuestra ayuda y la de otros líderes estudiantiles del país para participar en uno de sus proyectos, junto a la Comisión Nacional para el Mejoramiento de la Administración de Justicia.

A la Presidenta de la República y al Ministro de Educación Pública, de aquel entonces, los invitamos a la Toma de Posesión, pero no aparecieron. En su lugar, enviaron a sus subordinados. Nunca conocimos su posición oficial en torno a la idea. Casi tres años después, doña Laura Chinchilla envío un reconocimiento firmado, en la cual felicitaba a la institución por el incentivo de valores cívicos en la población estudiantil.

A lo largo del tiempo, muchos políticos y funcionarios públicos (entre los que se menciona a Epsy Campbell, Abril Gordienko, José María Villata, José Miguel Corrales y Luis Guillermo Solís) han tenido contacto con el sistema parlamentario del Colegio Humanístico Costarricense, con los cuales se mantuvieron interesantes diálogos.

Todas estas ideas fueron escuchadas y aún persiste el interés por seguir generando cambios. En el Colegio Humanístico, se cuenta con una excelente administración estudiantil, la cual mantiene proyectos de extensión, para continuar con dicho pregonar.

Hoy día, muchos son los defensores de estas ideas. En el informe ofrecido la Comisión Presidencial sobre Gobernabilidad Democrática (más conocida como 
Comisión de Notables) resaltan muchas ideas de corte parlamentarista. Como consecuencia, la actual Asamblea Legislativa conformó la Comisión de Reformas de Sistema Político, para estudiar cuán viable es instaurar esas propuestas en nuestro país.

Ahora bien, en realidad no se propone un cambio radical y extremo de sistema de gobierno, pues:

Costa Rica no está preparada para ello. Antes de implantar un cambio de tal magnitud, deberíamos sopesar las posibles consecuencias, en especial la probabilidad de inestabilidad política. Por ende, el tema deber ser puesto sobre la mesa de discusión en estos días (...), para que la ciudadanía costarricense empiece a discernir y esclarecer cuál camino elegiremos como nación (Villafuerte, 2015, p.24).

Es imprescindible cambiar muchos aspectos del sistema presidencialista, ojalá erradicarlos (por ejemplo, los antes mencionados). Ofrecemos solución a través de ciertos desaciertos del sistema parlamentarista, pero es innecesario sustituirlo todo. Hay raíces enfermas, pero no son todas. Estamos consientes de cuán difícil es cambiar de sistema de gobierno y del trabajo tan minucioso que se requiere (González, 2012, p.23). Compartimos la verdad escrita por Montenegro (2010):

No hay formulas de eficacia permanente. Las que más pueden aproximarse a una especie de permanencia son las que empiezan por admitir que no hay nada permanente y que, por ende, están dispuestas a sacrificar la rigidez dogmática de sus principios y posiciones, para adaptarse a las nuevas circunstancias. (...). El simple traslado de esquemas de un sitio a otro, de una a otra nación, es inoperante. Lo verdadero, lo justo y eficaz de una doctrina es el resultado de condiciones específicas de tiempo, espacio y circunstancia. (p.28)

Por ello nuestra esperanza está en contribuir al fortalecimiento de la democracia costarricense, mediante la sana participación ciudadana, con especial énfasis en la formación de una juventud capaz y activa. El ideal es que la democracia más antigua de América Latina, también sea la más sólida. Para lograr este objetivo, es necesario fomentar un liderazgo creativo y transparente, capaz de ofrecer las medidas requeridas para mejorar el país y conducir esta nación con cordura y decencia. No se habla de un dictador, tampoco de una utopía. Porque "tal vez una persona no pueda tapar el sol con un solo dedo, pero si cada uno ofreciera un 
dedo, o su mano, en instantes ese sol se ocultaría bajo las muchas sombras”, tal y como se dijo en un discurso ofrecido para el Traspaso de Poderes 2013-2014 (Vargas, 2013, p.49).

La esperanza más pequeña, a nivel institucional, "es que el proceso tenga continuidad por las demás generaciones” (Vargas, 2013, p.48).

Como se podrá observar, las anteriores ideas también fueron descritas de la siguiente manera:

Con todo lo desarrollado y por desarrollar en el Colegio Humanístico Costarricense, se le demuestra una vez más a la nación que sí hay jóvenes que se involucran efectivamente en los procesos que le competen, sin violencia y sin agredir las leyes de la República. El clamor que se levantó en el colegio, fue un clamor que pedía a los gobernantes transparencia, esfuerzo, diálogo y madurez. De esa misma forma, se demostró la presencia de jóvenes interesados en servir de apoyo y ofrecer consejo a los entes gubernamentales. Los representantes electos en la Toma de Posesión, expusieron con claridad que los jóvenes sirven para algo más que mover banderas en el día de las elecciones nacionales, y sí se pueden involucrar en procesos políticos. El Colegio Humanístico Costarricense con su laboratorio democrático y su crítica, exhibió la necesidad existente de buscar nuevas alternativas que favorezcan la gobernabilidad nacional y fortalezcan las debilidades de una de las democracias más longevas en Latinoamérica” (Rojas, Vargas y Villafuerte, 2013, pp.12-13).

\section{Relación con el Humanismo}

En este segmento se podría hablar y discutir sobre tesis enteras relacionadas con las Humanidades. Podríamos mencionar cómo el movimiento estudiantil parlamentarista llenó, en todos los participantes, cada una de las cinco necesidades básicas del ser humano, expuestas por el psicoterapeuta humanista Erich Fromm.

También podríamos reflexionar sobre cómo el mismo caos imperante en la política nacional condujo a un grupo de personas en el Colegio Humanístico a través del flujo de la actividad caótica, para que estos buscaran soluciones que trajeran cierto orden, siguiendo los preceptos de las siete leyes del caos, expuestas por John Briggs y David Peat. Pero no, eso no es el objetivo de este pequeño fragmento. 
Alfonso García (1996, p.20) defiende que toda la práctica de la política y del Humanismo en sí debe estar al servicio del ser humano. Por ende, el resto de cosas son secundarias. La democracia es el mejor mecanismo político para servirles a los demás. Por eso, debe ser cautelosamente protegida, para salvaguardarla de toda desavenencia negativa.

La esencia de cualquier forma de participación ciudadana se centra en el servicio a los demás. El producto de la vida en sociedad ha generado la necesidad de buscar soluciones colectivas y grupales, donde ceden muchos intereses particulares. En este punto, cuando por decisión personal lo colectivo prima sobre lo individual, se observa una forma de servicio, la cual impregna el mover político, además del crecimiento y superación de las personas (Instituto Interamericano sobre Derechos Humanos, 1997, pp.9-12).

El laboratorio democrático en el Colegio Humanístico Costarricense ha marcado la vida de quienes participaron en ella. Estamos convencidos de que hicimos lo correcto. Realizamos ciertas acciones memorables, las cuales han servido y podrán seguir sirviendo a muchas personas, algunas de las cuales nunca conoceremos.

Esa es la relación con el Humanismo. Algo sencillo, pero contundente. Por un momento, dejemos de pensar en el engranaje teórico de las Humanidades y pongamos en práctica de la que tanto se alardea. La esencia de todo conocimiento debe ser el estar al servir de los demás.

De hecho, esto fue mencionado como uno de los más grandes logros del movimiento estudiantil parlamentarista, en el acto protocolario de Traspaso de Poderes 2014-2015 (viernes 9 de mayo del 2014, Auditorio Clodomiro Picado), cuando se dijo: "queríamos sellar nuestra existencia, para que cuando fuéramos ancianos, recordáramos que en nuestra Casa de Enseñanza inició una vida marcada por el servicio a los demás”.

\section{Referencias}

Cervantes, O., (1987). Administración de las instituciones públicas. San José, Costa Rica: EUNED.

Delgado, I., (2012). Doce lecturas fundamentales de la ciencia política. San José, Costa Rica: EUNED. 
García Gutiérrez, A. (1996). Ensayo sobre un nuevo humanismo. Bogotá, Colombia: Disvén Publicidad-Editores.

Gonzales Solano, G. (2012). Principios de metodología jurídica. San José, Costa Rica: EUCR.

Hines, C. (comp.) (2011). Temas de Derecho Público: estudios en homenaje al Dr. Rafael González Ballar. San José, Costa Rica: Editorial ISOLMA.

Instituto Interamericano Sobre Derechos Humanos (1997). Participación Ciudadana. San José, Costa Rica: IIDH.

Maturana, H. (1995). La democracia es una obra de arte. Bogotá, Colombia: Editorial Magisterio.

Montenegro, W. (2010). Introducción a las doctrinas político-económicas. Distrito Federal, México: Fondo de Cultura Económica.

Muñoz, José \& otros (2009). El arte de hacer una campaña política. Distrito Federal, México: Estudios Estratégicos.

Programa Estado De La Nación (2014). Vigésimo Informe del Estado de la Nación. San José, Costa Rica: Programa Estado de la Nación.

Rojas, R., Vargas, M., Villafuerte, A. (2013). Ponencia: La experiencia pedagógica del Colegio Humanístico Costarricense. Liberia, Costa Rica: IV Encuentro de Humanistas.

Romero, J. (2000). La romana del diablo. Madrid, España: Editorial Marcial Pons.

Sáenz Carbonell, J. F. (2012). Los sistemas normativos en la Historia de Costa Rica. San José, Costa Rica: Editorial ISOLMA.

Vargas, E. \& otros (2013). II Reseña Histórica. Colegio Humanístico Costarricense. XV Aniversario de Creación. Heredia, Costa Rica: Universidad Nacional.

Villafuerte Vega, A. (2015). Cambios políticos por diferentes caminos. Semanario Universidad. San José, Costa Rica. p. 24. 
Villasuso, J.M. (2003). Procesos de cambio en Costa Rica. San José, Costa Rica: Fundación Friedrich Ebert.

Zúñiga, C. \& Jiménez, L. E. (2013). Sistemas políticos contemporáneos. Una visión tipológica. San José, Costa Rica: EUCR. 